\title{
Um olhar estrangeiro sobre a "etnografia implícita" dos portugueses na Goa quinhentista
}

\author{
A foreign look at the "implicit ethnography" of the Portuguese \\ in sixteenth-century Goa
}

\author{
THOMÁS A. S. HADDAD
}

Escola de Artes, Ciências e Humanidades da Universidade de São Paulo | EACH/USP

RESUMO Após trabalhar em Sevilha e Lisboa por alguns anos, o holandês Jan Huygen van Linschoten (c. 1563-1611) foi nomeado guarda-livros e secretário do recém-indicado arcebispo de Goa, o dominicanoVicente da Fonseca, em 1583. Ao retornar à Europa quase uma década depois, tendo vivido em Goa por mais de cinco anos, Linschoten começou a publicar relatos de viagem e instruções náuticas que encontraram extraordinário sucesso. Sua principal publicação, o Itinerario, foi editada em holandês por Cornelis Claesz em 1596 (com uma cópia avançada tendo sido entregue um ano antes à primeira frota holandesa que navegou para as Índias Orientais), e quase imediatamente traduzida para o inglês (1598) por sugestão de Richard Hakluyt, que recomendou o livro à Companhia das Índias Orientais da Inglaterra. Edições em latim, alemão e francês logo se seguiram. Sua extensa circulação e as valiosas instruções de navegação que continha fizeram dele um dos livros que mais propagaram o conhecimento sobre o Estado português da Índia pela Europa, tendo tido impacto direto sobre as empresas holandesas, britânicas, francesas e dinamarquesas rumo à Ásia. Além de um relato de viagem e compêndio da história natural indiana, o Itinerario também é uma longa meditação moral sobre os modos e atitudes dos portugueses em relação aos habitantes de Goa - sua "etnografia implícita" - e sobre sua falência em manter uma distância segura em relação a eles, o que representa uma avaliação negativa do próprio sistema de "conhecimento colonial" dos portugueses.

Palavras-chave Império português - conhecimento colonial - etnografia implícita - Jan Huygen van Linschoten

\begin{abstract}
After working as a merchant in Seville and in Lisbon for a few years, the Dutchman, Jan Huygen van Linschoten (1563-1611), was named book-keeper and secretary to the newly appointed archbishop of Goa, the Dominican Vicente da Fonseca, in 1583. Upon his return to Europe almost a decade later, having lived in Goa for more than five years, Linschoten started publishing travel accounts and sailing instructions that met with extraordinary success. His foremost publication, the Itinerario, published in Dutch in 1596 by Cornelis Claesz (an advance copy being given one year earlier to the first Dutch fleet sailing to the East Indies), was promptly translated into English (1598) upon the counsel of Richard Hakluyt, who recommended the book to the British East India Company. Latin, German and French editions followed suit. Its wide circulation and invaluable navigational instruction turned it into one of the books that did the most to spread knowledge about the situation of the Portuguese State of India throughout Europe, having had direct impact on Dutch, British, French and Danish ventures into Asia. Being somewhere between a travel account and a compendium of Indian natural history, the Itinerario is also, however, a long meditation with moral overtones on Portuguese manners and attitudes toward Goans - the formers' "implicit ethnography" - and about their failure in keeping a safe distance from the latter, what represents a negative evaluation of the very "colonial knowledge" system of the Portuguese.
\end{abstract}

Key words Portuguese Empire - colonial knowledge - implicit ethnography - Jan Huyghen van Linschoten 


\section{Introdução: "conhecimento colonial” e "etnografias implícitas”}

Em dezembro de 1797, o governador de Angola, D. Miguel Antônio de Melo, escreveu para o ministro D. Rodrigo de Souza Coutinho reclamando que o melhor mapa da região, compilado em 1790 pelo engenheiro Luís Cândido Pinheiro Furtado, já não prestava.

${ }^{1}$ Além de não ter sido traçado com a ajuda de instrumentos matemáticos, mas sim recorrendo à informação local sobre os tempos de trajeto entre os sítios, os vilarejos que representava não existiam mais: "quase diariamente", relata o governador, os nativos moviam suas vilas de cabanas de palha por grandes distâncias. 0 que no mapa aparece como uma área populada, em um dia já está deserto, habitado apenas por animais selvagens.

Aqui se trata da apreensão do espaço, mas esse parece ser o caráter elusivo de todos os objetos do "conhecimento colonial". ${ }^{2}$ Podemos tentar começar a compreendê-lo enumerando suas tarefas. Quais são elas? Cartografar, inventariar a natureza, classificar seus produtos, defender o colonizador de suas febres, seus ataques, suas doenças, sua escassez; compreender as línguas, estabelecer a comunicação, catalogar os costumes, os ritos, as cerimônias religiosas e políticas. E quais são seus fins? Administrar e ordenar os territórios, a fiscalidade e a economia, subjugar as populações. Ou, como sintetiza a historiadora portuguesa Ângela Barreto Xavier, "a vontade de ter 'império sobre o mundo' requeria conhecer esse mundo sobre o qual se queria exercer o imperium". ${ }^{3}$ Mas esse mundo, entretanto, parece escapar o tempo todo a integrar-se plenamente na pretensão totalizante do saber que se constitui a seu respeito. Um mundo que reage aos mais recentes mapas, que exige a revisão dos últimos inventários, que traz uma infinidade de exceções às regras que pareciam enfim ter sido enunciadas. Trata-se do caráter sempre provisório e incompleto do conhecimento colonial.

Mas nem sempre essa foi uma opinião corrente. Primeiro, pensou-se no conhecimento colonial simplesmente como conhecimento europeu alimentado pelo grande repositório de informações que eram as terras e as gentes que encontravam em sua expansão. Um conhecimento prístino e puro, produzido por grandes sábios em gabinetes cheios de material coletado mundo afora. Depois de pronto na Europa, esse conhecimento lentamente se difundia por suas possessões, que não podiam senão se curvar a sua força epistêmica e sua eficácia material. ${ }^{4}$ Lentamente, os poderes coloniais assentiam em implantar sucedâneos ou arremedos de suas instituições de saber nas possessões ultramarinas, em pactos com as elites locais que sobreviviam à própria emancipação política.

Posteriormente, esse difusionismo ganhou tinturas radicais, especialmente nas mãos dos teóricos do "saber e poder". Às vezes sofisticado, às vezes mera trivialização das reflexões de Michel Foucault, o conhecimento colonial passou a ser visto como instrumento de dominação, tão importante quanto a força militar e a exploração econômica - na verdade, passou a ser visto como fundamental para o próprio exercício da força. Quando bem aplicada, essa perspectiva teórica nos deu estudos brilhantes: reflexões profundas sobre o lugar dos saberes na administração dos impérios, na exploração intensiva das populações e da natureza, na conquista dos territórios. 0 movimento historiográfico "Ciência e Impérios", que muito floresceu na década de 1990 e segue produzindo análises notáveis, é o exemplo mais destacado. ${ }^{5}$ Com teóricos informados pelo pós-colonialismo à moda de Edward Said, muito nos revelou sobre os universos discursivos do conhecimento europeu sobre o resto do mundo, sua pretensão normativa e controladora, e o processo de sepultamento de epistemologias locais por eles engendradas (com a conivência ocasional das elites crioulas, elas próprias em busca de um lugar no discurso).

Mas, nessas análises, o difusionismo permaneceu: o puro-sangue europeu do conhecimento colonial não foi posto em dúvida. Concedeu-se apenas que ele não se espalhou pelo mundo apenas por ser verdadeiro, mas pela força de seus agentes. Algumas das melhores narrativas dessa escola histórica nos falam de resistência: como sistemas locais de conhecimento procuram sobreviver, para finalmente se dobrar à invencibilidade da modernidade científica europeia, garantida por seus recursos superiores. ${ }^{6}$

Recentemente, porém, o acúmulo de narrativas de resistência começou a abrir um flanco no difusionismo. Será que nessa resistência os sistemas de conhecimento locais não causam transformações no conhecimento europeu, 
que nunca terá sido, portanto, puro? Será que a modernidade não é, na verdade, fruto da hibridização, e não ocorreu na Europa e daí para o resto do mundo, mas sim em toda parte ao mesmo tempo? Será, enfim, que os sujeitos coloniais não tiveram também sua própria agência na formação do conhecimento a respeito de si e de seus espaços? Em vez de alimentar uma Europa ávida por informações e instituições ávidas por poder, para dali se espalhar de volta sobre o mundo, o conhecimento moderno pode ter sido produzido em todo lugar, por uma multiplicidade de agentes, intermediários, facilitadores, informantes, todos envolvidos em trocas e negociações constantes, locais e globais, quase sempre assimétricas, mas ainda assim relacionais. Nessas trocas e negociações é que se terá forjado a modernidade global, inclusive em ciência, e não isoladamente nas instituições europeias. ${ }^{?}$

Disso emerge um "conhecimento colonial" que pode ser usado como instrumento de poder e dominação, sim, mas de uma dominação sempre parcial, sempre incompleta. Aqui é que recuperamos os territórios que escapam à apreensão, a natureza que surpreende, as populações que encontram formas de resistir e de se adaptar, de que falamos acima. Na produção de conhecimento sobre suas colônias e impérios, e também na produção de conhecimento em suas colônias e impérios, os poderes europeus resultam transformados em sua própria epistemologia; e, por mais localmente lastreados que sejam os enunciados e as práticas da ciência, é nessas idas e vindas circulatórias que ela se universaliza.

Implicitamente, porém, em toda essa discussão se costuma tratar apenas dos sistemas de conhecimento de algum modo formalizados: a cartografia, a geografia, as ciências descritivas, a medicina etc. - saberes incontestavelmente necessários às formas de controle coloniais. ${ }^{8} 0$ governo dos povos, a administração de um império, requerem, no entanto, outras formas de conhecimento também. Um conhecimento das coisas sociais, o controle disciplinar de si e do outro, o conhecimento das paixões da alma. Trata-se de saberes mais tácitos, relacionados com o comportamento e o controle das formas de interação. A "zona de contato" colonial, ${ }^{9}$ onde se desenrola 0 encontro entre as culturas e gentes envolvidas, exige habilidades dessa natureza, não apenas mapas, descrições da fauna e da flora, técnicas de mineração ou receituários de farmacopeia. Muito antes de se formalizar, existe uma pré-etnografia que permeia o encontro e permanece informando as ações e as relações na zona de contato. É justamente nessa zona fluida que ocorrem as negociações, os intercâmbios e a hibridização, e de saber comportar-se nela depende o sucesso de cada parte na conquista de seus objetivos.

Stuart Schwartz nos fala de uma "etnografia implícita" que precede e informa todos os futuros tratados descritivos e tentativas de apreensão formalizada dos hábitos, ritos e práticas de uma população.j Toda a etnografia europeia, do humanismo classicizante ao racialismo biológico oitocentista, passando pelo universalismo progressista da llustração, terá sido continuamente informada pelas etnografias implícitas carregadas (em via de mão dupla) por marinheiros, viajantes, missionários, mercadores, agentes administrativos, soldados. Acompanhemos Schwartz:

[...] uma "etnografia implícita" [sempre] existiu nos dois lados do encontro. Membros de cada sociedade mantinham ideias, frequentemente não enunciadas, de si próprios e dos "outros", e das coisas que lhes davam tais identidades [...]. Essas compreensões eram frequentemente implícitas no sentido de não serem enunciadas ou de serem pressupostas, um tipo de conhecimento ou senso comum que não tinha de ser articulado, mas que permeava a maneira pela qual as pessoas pensavam ou agiam. ${ }^{11}$

Precedendo temporal e epistemologicamente à produção etnográfica formal, espalhada como senso comum ou "conhecimento tácito", a etnografia implícita dos encontros e das zonas de contato é uma forma de saber fundamental a todo o conhecimento colonial. Além disso, ela circula amplamente: cartas, relatos, literatura de viagens e outros gêneros e meios alimentam os pressupostos de uma cultura em relação a outras e a si mesma, reforçando ou derrubando estereótipos, mitos e formas de apreensão dos objetos próprios das "etnografias explícitas" (intencionais, estruturadas, com pretensões formalizantes ou sistêmicas...): religião, cor, parentescos, gênero, formas de organização política etc.

Schwartz ainda salienta a natureza dinâmica das etnografias implícitas da primeira modernidade (no contexto dos encontros comerciais, militares, diplomáticos, evangelizadores ou plenamente coloniais europeus com outras culturas) 
de uma maneira notavelmente próxima do que dissemos anteriormente a respeito do caráter localmente negociado (e globalmente significativo) do conhecimento "científico". Na zona de contato continuamente ocorreram reajustes da percepção de si e do outro e foram produzidos corpos tácitos de saberes sobre o mundo, em uma "tensão dinâmica entre compreensões e expectativas prévias e novas observações e experiências".12

Pertence também ao universo da história das ciências, e particularmente aos estudos preocupados com os antecedentes dos sistemas de conhecimento coloniais, a atenção para com as etnografias implícitas. Ao informar a lógica das ações imperiais, elas criaram modelos que se propagaram através de redes de correspondências, crônicas, tratados impressos, regimentos e instruções, dentro e para fora dos impérios diretamente envolvidos. Fundamentaram projetos concorrentes, epistemologias alternativas, e variadas formas de apreensão das culturas e, evidentemente, da inseparável natureza. São, em uma palavra, os pressupostos tácitos da própria modernidade global, também em sua forma científica, e merecem atenção.

De que forma a discussão precedente se refere ao Império colonial português? Comecemos recordando que a expansão portuguesa antecede a das outras nações europeias. Muitos primeiros contatos e primeiras experiências de sociedades coloniais tiveram como um lado protagonista os portugueses. Eles tiveram de mobilizar as etnografias implícitas na construção de corpos de conhecimento sobre as zonas de contato em uma escala maciça, desvendando para si mesmos religiões, sistemas de governo, parentesco e potencialidades naturais de variados territórios. Tiveram de empregá-las também na tentativa de governar sua própria presença em uma vasta rede de portos, feitorias, fortes e territórios espalhada pelo mundo.

Mas, em fins do século XVI, seu império na Ásia já tinha passado, na opinião mesma de muitos contemporâneos, pelo período de glórias, e se encontrava em franca decadência. 0 que tinha "dado errado"? Falta de poder militar? Concorrência econômica? Ineficiência administrativa? Ou se pode localizar o declínio em algum lugar do terreno nebuloso dos conhecimentos de si em relação ao outro? Um observador estrangeiro da sociedade luso-indiana da década de 1580 parece ter enxergado justamente isso: por não terem o conhecimento das consequências da hibridização biológica e cultural, os portugueses tinham falido no Oriente. Seu olhar estrangeiro é ainda mais revelador, pois se constitui em um discurso às vezes impiedoso sobre o comportamento dos portugueses na zona de contato que Goa representava nessa época, em relação aos traços e atitudes culturais. A mensagem que ele leva a seus leitores de fora do Império Português, holandeses e ingleses, é por eles interpretada como um convite à implantação de outros modelos coloniais, tributários de projetos imperiais alternativos, no Oriente. Ela contém uma etnografia (implícita) da própria etnografia implícita que vinha informando os portugueses no Estado da Índia, e terá seu papel na implantação das companhias comerciais dos Estados do norte da Europa por aquelas partes. Que essas companhias tenham atuado, por sua vez, como redes de circulação de conhecimento científico e médico por toda a primeira modernidade, como estudos recentes têm alertado claramente, ${ }^{13}$ apenas reforça 0 interesse em compreender 0 relato de Linschoten.

\section{Apontamentos para uma vida de Linschoten ${ }^{14}$}

0 observador ao qual nos referimos, Jan Huygen van Linschoten, pode ser considerado um tipo ideal do viajante curioso de fins do século XVI, o homem que viajava para experimentar empiricamente a diversidade do mundo. Dono de uma educação modesta, ele parece ter seguido instintivamente tudo aquilo que os manuais apodêmicos (a versão secular dos guias de peregrinos) de sua época prescreviam para o viajante. Ele aparentemente mantinha um diário de observações - não de sentimentos, como seria tão comum no século XVIII - e organizava diariamente os registros do que vira, anotando sobre costumes, fauna e flora, eventos políticos e militares. Vivendo em Goa, mantinha contato com informantes locais e com outros viajantes, que the podiam relatar sobre lugares mais distantes, aos quais não tinha acesso: correspondia-se com um flamengo que vivia na costa de Coromandel, conversou com ingleses e venezianos 
sobre Ormuz, a Pérsia e a rota terrestre para o Oriente, com um capitão de navio sobre as Molucas, com um escravo sobre o caminho de Moçambique pelo oeste africano, e extraiu capítulos inteiros do livro que viria a publicar na Europa da experiência de um holandês que estivera em Macau e no Japão como canhoneiro. Exatamente como sugerido pela apodêmica, organizou uma pequena coleção: duas aves-do-paraíso das llhas das Especiarias, papel chinês com ideogramas, canetas, tinta, um par de palitos para alimentação, textos indianos escritos em folhas de palmeira, sinos genitais usados por homens da Birmânia... Tinha livros também, como a impressão goense dos Colóquios dos simples de Garcia de Orta, esse grande inventário da natureza indiana, e manuscritos que copiava, com destaque para uma infinidade de roteiros náuticos portugueses e espanhóis. Tudo isso encontrou um lugar na obra que publicaria em 1596, depois de voltar à Europa, o /tinerario. ${ }^{15}$

Talvez nada resuma melhor seu desejo de conhecer o mundo que suas próprias palavras no início desse livro:

Sendo jovem, e vivendo ociosamente em meu país natal, às vezes me aplicando à leitura de histórias e estranhas aventuras, de que eu não tirava pequeno deleite, encontrei minha mente tão decidida a ver e viajar para estranhos países, e lá buscar alguma aventura, que, no fim, para me satisfazer, eu estava determinado, e completamente resolvido, a deixar meu país natal por algum tempo, e meus amigos (ainda que isso me entristecesse). ${ }^{16}$

Temos ainda o testemunho de uma carta a seus pais, escrita de Goa, em 1584:

Não há tempo mais desperdiçado do que quando um jovem fica na cozinha de sua mãe como um bebê, sem saber o que é a pobreza, ou o luxo, ou o que se encontra no mundo, uma ignorância que é frequentemente a causa da sua ruína. ${ }^{17}$

Essa infância povoada pelo desejo de ver o mundo começara em Haarlem, no norte da Holanda, onde ele nascera, em 1562 ou $1563,^{18}$ no seio de uma família católica. Seu pai era dono de uma estalagem e tinha filhos mais velhos, de outros casamentos. Em 1572, Haarlem se uniu à revolta do príncipe Guilherme de Orange e os espanhóis foram expulsos, somente para voltar no ano seguinte, o que deve ter motivado a decisão da família de partir para Enkhuizen, um porto mais ao norte que não recaíra em mãos espanholas. Ele nos conta que, em 1576, dois de seus meio-irmãos mais velhos partiram para Sevilha, a despeito da guerra (como ainda iria acontecer por muito tempo, nem Espanha nem Holanda podiam se entregar ao luxo de cortar relações comerciais entre si). Em 1579, o jovem Jan Huygen iria se unir aos irmãos.

Ao chegar a Sevilha, um de seus irmãos já havia partido para se juntar à corte em Madri, e tudo indica que a busca por posições na elite administrativa da monarquia espanhola era o objetivo da família. 0 irmão que permanecera em Sevilha logo encontrou um cargo junto a um embaixador espanhol em viagem à Itália. Aquele que fora para Madri se envolveu nos preparativos para a proclamação de Filipe II em Lisboa, e rumou para lá no início de 1580, como funcionário de um secretário real. Linschoten em breve se juntaria a ele, trabalhando para um mercador.

Por indicação desse irmão, que lograra em tempo empregar-se como escrivão em um navio da frota que partiria de Lisboa para a Ásia na Sexta-feira Santa de 1583, Linschoten conseguiu uma posição junto ao recém-indicado arcebispo de Goa, o dominicano D. Vicente da Fonseca, ${ }^{19}$ que iria para as Índias na mesma carreira. Em 5 de agosto desse ano, a frota atingiria Moçambique, a principal parada na costa oriental da África, onde permaneceria por quinze dias. Mais tarde, Linschoten teria muito a escrever sobre Moçambique, mas agora sua jornada estava apenas começando. Em 21 de setembro, finalmente Goa seria atingida.

Sé metropolitana arcebispal, residência do vice-rei, cabeça do Estado da Índia, Goa seria a casa de Linschoten por mais de cinco anos. Tudo indica que a confiança do arcebispo era irrestrita, e ele em breve se tornou um de seus principais secretários e guarda-livros. Certamente a biblioteca do prelado e sua rede de relações foram também utilizadas por Linschoten, que não perdeu tempo em começar a anotar e desenhar tudo o que via e ouvia. 
No início de 1587, D. Vicente da Fonseca partiu de volta a Lisboa, mas com a intenção de retornar. Linschoten permaneceu em Goa, encarregado do recolhimento dos benefícios e mantenedor da casa do arcebispo. Na primavera do ano seguinte, ele viria a saber da morte do dominicano em alto-mar. Isso, combinado a notícias da morte do pai e do irmão, deve tê-lo instado a voltar para a Europa, para onde partiu no início de 1589, empregado como "feitor da pimenta do rei". A viagem de volta foi muito atribulada: após rápidas estâncias em Cochim e nas ilhas de Sta. Helena e Ascensão (das quais ele nos deixou perfis costeiros), a frota teve de aportar nos Açores, em Angra da llha Terceira, acossada por corsários ingleses. Um dos navios naufragou, e a salva e desembaraço de sua carga ocuparia Linschoten por dois anos mais. Só em setembro de 1592 ele chegaria novamente a Enkhuizen.

Nessa cidade, ele logo se conectou ao círculo de Bernardus Paludanus, médico, viajante e dono de um gabinete de curiosidades de fama internacional, e de Lucas Jansz Waghenaer, cartógrafo com importantes laços políticos nos Estados Gerais das Províncias Unidas. Deve ter sido nesse círculo que surgiu o estímulo para que escrevesse um relato de sua viagem ao Oriente, a ligação com o editor Cornelis Claesz, de Amsterdã, e também o desejo de conversão ao calvinismo. Na década de 1590, o círculo de Enkhuizen, como tantos outros dos Países Baixos, devia estar entusiasmado com os sucessos do príncipe Maurício contra os espanhóis, abrindo novas perspectivas políticas, com as possibilidades da Igreja Reformada, e com as possibilidades econômicas que se anunciavam na esteira de um poderio marítimo então descoberto.

Em meio a esse ambiente de otimismo nacional, em fins de 1594, o livro de Linschoten deve ter estado substancialmente completo, já com a licença de impressão pela casa de Claesz. Foi dividido em três partes: primeiro, 0 Itinerario propriamente dito, dedicado aos Estados Gerais, contendo a descrição de todo o Estado da Índia e muito mais: do Cabo a Nagasaki, passando pela costa oriental da África, o Ceilão, as Costas do Malabar e de Coromandel, Diu, Bengala, Malaca, as Molucas e Macau, com destaque, obviamente, para Goa. Trinta ilustrações, que já no frontispício são anunciadas como baseadas nos desenhos do próprio Linschoten, adornam o livro: elas representam fauna e flora, costumes, vestimentas, rituais religiosos e cerimônias políticas de diversos lugares, incluindo dos portugueses em Goa. 0 texto afirma que foram feitas "a partir da realidade", salientando seu caráter empírico e experiencial, 0 que obviamente traz o problema de estabelecer como Linschoten representou cenas de lugares em que não esteve (mesmo considerando o caráter altamente convergente da Goa de seu tempo). Ainda há seis mapas acompanhando essa parte do livro, preparados pela família Van Langren a partir de originais manuscritos de Bartolomeu Lasso, que tinham sido obtidos em Portugal, em uma missão secreta de 1592 (Claesz já imprimira um desses mapas, na versão de Petrus Plancius, futuro hidrógrafo da Companhia das Índias Orientais). A segunda parte contém 67 roteiros marítimos copiados por Linschoten de pilotos portugueses e espanhóis, incluindo até as rotas do Pacífico entre Ásia e América, e a rota do Atlântico entre Portugal e Brasil. Aos roteiros, segue-se ainda uma descrição pormenorizada dos domínios e rendas da coroa espanhola em fins da década de 1580, 0 que atesta a qualidade do material a que 0 autor teve acesso. Finalmente, a terceira parte constitui uma descrição da África Ocidental e da América, baseada em certo número de fontes, incluindo o jesuíta José de Acosta, de cuja História natural y moral Linschoten publicaria uma tradução em 1598.

A obra completa só seria impressa em 1596, mas é certo que a primeira frota holandesa a rumar para as Índias Orientais, em 1595, já possuía uma cópia impressa da segunda parte e muito provavelmente manuscritos da primeira. Em 1598, o livro foi traduzido para o inglês, por recomendação de Richard Hakluyt, que ainda viria a recomendar a obra à Companhia das Índias Orientais da Inglaterra. Um ano depois, duas edições em latim apareceriam, uma delas na coleção oriental dos De Bry de Frankfurt. Em breve se seguiriam versões em francês e alemão. A circulação foi ampla, e certamente Linschoten foi fundamental na abertura do Índico às nações do norte da Europa. Ernst van den Boogaart não hesitou em chamá-lo de "o livro que lançou mil navios" ${ }^{20}$ Com tudo isso, porém, o Itinerario não pode ser considerado como o resumo de um plano de ataque holandês à Ásia Portuguesa, como já pretenderam alguns comentadores. Colagem desigual de fontes literárias, roteiros ibéricos, informações de outros viajantes e sobretudo da experiência do próprio autor em Goa, a obra é antes, ou ao menos em seu coração, uma meditação moral sobre o modo de vida dos portugueses em Goa e suas relações com as populações e a natureza locais. 
Ainda na década de 1590, Linschoten participaria de duas expedições holandesas ao Ártico, que tinham o objetivo de encontrar a passagem nordeste para a Ásia. Casado com a filha de um magistrado, ocupando posições na administração de Enkhuizen, viria a falecer em 1611.

\section{A Goa de Linschoten}

Quando Linschoten aportou em Goa, o Estado da Índia já contava quase oitenta anos, e a cidade já estava nas mãos dos portugueses havia cerca de 75 anos. ${ }^{21}$ Já não era mais a Goa Dourada dos cronistas portugueses de meados do século, capital cosmopolita e tolerante, como querem alguns, ${ }^{22}$ de um império marítimo bem-sucedido. Para Linschoten, Goa transpira decadência, lotada de nativos idólatras, portugueses preguiçosos e mulheres lascivas. Ele nota a corrupção do governo, o estilo de vida decaído dos soldados, a entrega dos mercadores à caftinagem. É uma narrativa do que, para ele e seus leitores, representa o insucesso da empreitada oriental portuguesa. Mas o que dá 0 tom de sua narrativa, e que aqui vamos explorar, é que não há suficiente distância entre portugueses e indianos. Pelo contrário, a mistura biológica, econômica e cultural é o que Linschoten não se cansa de denunciar. De suas páginas, resulta a sensação de que os portugueses faliram em construir um sistema de conhecimento colonial eficiente, baseado em uma clara separação entre culturas. Obviamente a sustentação da presença portuguesa na Índia até 1961 refuta fragorosamente o quadro pintado por Linschoten, mas nosso interesse é justamente explicitar esse quadro (que, não podemos esquecer, ele traça com seus patronos holandeses em mente).

Goa ocupa diversos capítulos da primeira parte do livro, desiguais em extensão, estratégia narrativa, fontes utilizadas e, podemos dizer, intenção. Ela primeiro aparece, de passagem, em uma descrição das costas do oeste do subcontinente indiano. Aqui Linschoten se limita a observações muito gerais, principalmente sobre a geografia do território e a distribuição de populações. Vários capítulos à frente, a ilha reaparece, agora em sua história política prévia à conquista portuguesa. Após novo interstício, nove capítulos são quase inteiramente dedicados a Goa, e é aqui que se localiza o centro de toda a narrativa do Itinerario. Com um olhar que escrutina tanto o colonizado quanto o colonizador, Linschoten desenvolve um série de temas, que têm sempre em seu cerne a percepção da ausência de distância entre uns e outros: a miscigenação, o comportamento das indianas casadas com os portugueses, o modo de vida dos soldados, os hábitos dos brâmanes, judeus, muçulmanos e cristãos, o governo.

Há espaço ainda para uma apresentação mais pormenorizada do território, sua hidrografia, principais produtos, doenças comuns (e suas formas de tratamento pelos portugueses e pelos indianos), sistemas de pesos e medidas e questões monetárias. Mais à frente, seguem-se 45 capítulos sobre fauna, flora, pedras preciosas e especiarias que não são específicos sobre Goa, mas frequentemente se referem a elementos que nela ocorrem, ou que Linschoten diz ter visto no mercado da cidade. Quase todo o material botânico é extraído diretamente de Garcia de Orta e Cristóvão da Costa, complementado por ilustrações e comentários de Paludanus (que, incidentalmente, era um correspondente assíduo de Clusius, responsável pela adaptação de Orta para o latim).

Nessas descrições do mundo natural, Linschoten inclui habilmente o elemento humano: os animais são apresentados em conexão com cerimônias de que participam e usos que deles se fazem; as plantas são explicitamente caracterizadas como as mais comuns, aquelas que integram a vida cotidiana; e as pedras comparecem sempre associadas a seu interesse econômico. Interessantemente, não há espaço para o maravilhoso: nem animais fantásticos, antropomorfizados, nem plantas ou minerais com propriedades curativas milagrosas. Tampouco nas suas observações sobre história, política, religião e costumes, ou no último capítulo, uma coleção de anedotas, encontramos traços desse maravilhoso que tantas vezes povoou os relatos sobre a Índia, tornando-a um horizonte onírico da Europa. ${ }^{23}$ Não encontramos homens de centenas de anos, adivinhos infalíveis, híbridos, gigantes... Talvez o decantado experiencialismo, que terá, segundo alguns ${ }^{24}$ caracterizado a episteme quinhentista portuguesa, sem deixar lugar para mais que a observação, tenha encontrado em Linschoten um cultor. 
Mas é nos capítulos sobre as vidas entrecruzadas de portugueses e indianos que 0 autor mais revela sua condição de observador, de terceiro elemento no mundo luso-indiano. Sem se identificar com os indianos ou residentes estrangeiros de Goa, obviamente, mas também sem posicionar-se ao lado de seus empregadores portugueses, ele consegue lançar um duplo olhar, um olhar de fora, sobre ambos os lados. Como ressaltou lvo Kamps, ${ }^{25} 0$ editor inglês de 1598, John Wolfe parece já ter percebido isso. Em um notável prefácio que antepõe ao Itinerario, Wolfe recorre a dois diálogos de Luciano de Samósata para caracterizar a posição de Linschoten. No primeiro diálogo citado, o barqueiro Caronte e o mensageiro Mercúrio recebem permissão de Plutão para deixar o subterrâneo e satisfazer sua curiosidade sobre o mundo e sobre as ações dos homens. Eles empilham quatro montanhas e, sentados no topo, observam não só os mares e cidades, mas também os discursos, modos e ações dos homens. No outro diálogo citado, Menipo toma asas emprestadas e voa para longe da Terra, para além da Lua, do Sol e do habitáculo dos deuses, para, dessa distância, observar as ações dos homens. Wolfe sustenta que Linschoten observa exatamente da mesma maneira, de longe. Deve ter sido claro para o leitor do século XVI, como é para nós, que o autor, diferentemente dos portugueses que ele retrata, não se mistura com os objetos de seu olhar. A chave da boa observação de Linschoten, conforme parece insinuar o prefaciador, é a perspectiva. Ele mantém uma distância segura e, por mais associado que tenha estado com seus empregadores em Goa, jamais será um deles.

0 primeiro tema relevante para nós em que Linschoten toca na sua narrativa da decadência do Estado da Índia é a miscigenação. Ele inicia o capítulo que dedica a esse assunto indo diretamente ao ponto:

\begin{abstract}
Muitos portugueses na Índia são casados com as mulheres naturais do país, e as crianças que deles procedem são chamadas mestiços, isto é, meios-nativos. Esses mestiços são comumente de cor amarelada, ainda que haja muitas mulheres entre eles que são formosas e bem-constituidas. Os filhos de [ambos os pais] portugueses, tanto meninos quanto meninas, que nascem na Índia, são chamados castiços, e são em tudo como os portugueses, diferindo apenas um pouco na cor, pois tendem a uma coloração amarela: os filhos desses castiços são amarelos, e em tudo como os mestiços, e os filhos dos mestiços têm cor eforma como os nativos do país, de modo que a posteridade dos portugueses, tanto homens quanto mulheres, no terceiro grau, parece de indianos nativos, em cor e forma. ${ }^{26}$
\end{abstract}

Parte do argumento dá a impressão de ser de caráter "biológico" (e aqui as aspas em torno dessa palavra são fundamentais): a mistura de raças, representada pelos mestiços, apaga as características portuguesas, tornando a prole em tudo igual aos nativos. Mas é notável que os castiços, filhos de pai e mãe portugueses (uma raridade, dada a escassez de mulheres do Reino no Estado da Índia), já apresentem uma diferença de cor, pelo simples fato de terem nascido na Ásia. Por serem aleitados por amas indianas (um argumento comum na época, também ele de sabor "biologizante", mas que não é mobilizado explicitamente por Linschoten), ou simplesmente por nascerem fora da Europa, os castiços já são uma raça menos europeia - e, após quase um século de presença na Índia, conclui-se que os portugueses já deveriam estar muito decaídos. À contaminação do sangue pode somar-se uma contaminação cultural, mas que também tem consequências raciais. 0 casamento entre castiços já resulta em uma prole que não se diferencia dos próprios mestiços, que têm sangue indiano (seja pelo acúmulo da amamentação por indianas em duas gerações, seja por pura e simples contaminação - o texto não deixa isso claro). Os filhos dos mestiços, por sua vez, já são em tudo como os locais. De um modo ou de outro, reproduzir-se no Oriente faz os portugueses decaírem em poucas gerações - ou, ao menos, os faz menos europeus.

Ora, Afonso de Albuquerque, arquiteto do Estado da Índia, tinha, na segunda década do século XVI, pouco após a conquista de Goa, erigido a política de casamentos mistos em um dos pilares da colonização. ${ }^{27}$ Em sua percepção, isso reforçaria importantes alianças locais e desequilibraria a estrutura social em favor dos interesses portugueses. A Coroa adotou o plano de Albuquerque e concedeu privilégios regulares aos soldados (como eram chamados, por seu ofício obrigatório, todos os portugueses que imigravam solteiros para a Ásia) que se casassem com moças locais, até o século XVIII. A princípio, e do ponto de vista oficial, somente a limpeza de sangue à moda ibérica (isto é, ausência de antepassados judeus ou mouriscos) deveria ser considerada como elemento de distinção na sociedade indo-portuguesa: ter antepassados indianos convertidos não deveria ser um ponto negativo (além da limpeza de 
sangue, os outros elementos estruturantes da distinção nessa sociedade seriam o estatuto de nobreza e 0 estado civil, com a clivagem básica se dando entre soldados e casados). Linschoten, entretanto, parece se alinhar ao lado dos muitos portugueses que, desde os tempos de Albuquerque, desconfiavam dos casamentos mistos, expandindo a noção de limpeza de sangue para incluir também os conversos das religiões hindus, considerados como "raça infecta". Deve-se notar, de todo modo, que ele não adere ao vocabulário da limpeza de sangue, que mistura 0 estatuto religioso com a classificação racial: Linschoten limita-se a narrar o desaparecimento das características portuguesas no ambiente colonial.

Ainda quanto ao partido contrário à política de casamentos, como já demonstrado há muito tempo por Charles Boxer ${ }^{28}$ foi forte em toda a história colonial de Goa, e sistematicamente promoveu uma desconfiança generalizada nos mestiços e mesmo nos castiços. No caso das ordens religiosas, o veto à presença de mestiços foi insuperável até 0 século XVIII, pelo menos. Boxer acumula exemplos de declarações de missionários das ordens deplorando a inadequação destes (e, mais ainda, dos indígenas, naturalmente) aos seus quadros, ainda que os tolerem e até estimulem no clero secular. 0 partido antimiscigenação também foi poderoso entre governadores e vice-reis, que pareciam sistematicamente preferir reinóis recém-chegados e inexperientes a mestiços com longos anos de serviço, na distribuição dos cargos administrativos. A Coroa tentou muitas vezes, e sempre sem sucesso, impor a preferência por mestiços, mas a resistência de seus mais altos representantes foi invariavelmente ferrenha.

Parece haver, portanto, uma clivagem nos saberes raciais dos próprios portugueses e, consequentemente, nas lógicas de ação por eles adotadas - ou seja, a coexistência de duas grandes modalidades em suas percepções implícitas sobre as formas de vida na zona de contato: a prática oficial, fundada na apreensão de Albuquerque das realidades do contato, e a prática discriminatória generalizada, que Linschoten parece subscrever (ainda que, insistimos, sem adotar a linguagem da limpeza de sangue). A mensagem parece ser de que, se quisessem manter suas características, os holandeses deveriam evitar a miscigenação e mesmo a reprodução nessas terras distantes. A experiência portuguesa com os casamentos mistos não deveria ser copiada.

Mas Linschoten não poupa os próprios portugueses de sua observação implicitamente etnográfica - dentro mesmo da Europa há diferenças notáveis que ele quer registrar para seus leitores do norte. Assim, após a apresentação das raças, ele nos explica no mesmo parágrafo que todos os portugueses em Goa - reinóis ou mestiços, não importa - estão inseridos em uma rede comercial que une a cidade a Bengala, Malaca, Cambaia e China, e que seu lugar na capital da Índia Portuguesa é, por excelência, o mercado. No mercado, os portugueses encontram-se com gente de "todas as nações da Índia", e comerciam em tudo. Merece destaque o comércio de escravos em que eles se envolvem: "homens e mulheres, jovens e velhos, que são diariamente vendidos ali, como bestas entre nós" 29 "Entre nós", entre holandeses, diz-nos Linschoten. Essa nação comercia homens como "nós" fazemos com bestas. Ele continua: todos, a começar pelos imigrantes reinóis, se envolvem com a escravidão, mantendo "12, às vezes 20 , e às vezes 30 " cativos, que põem a ganho em todas as atividades, da venda de frutas em conserva à prostituição. "Portugueses e mestiços nunca trabalham", informa ele a seu mundo calvinista. Ou os portugueses já chegam degradados, ou viver na Índia resulta nessa consequência; não ficamos sabendo pelo texto.

Pequenos detalhes de comportamento são apontados por Linschoten de maneira muito reveladora. Descrevendo os copos usados pelos portugueses e mestiços para tomar água, ele nota que são de feitio indiano, moldados de forma a permitir que se sorva o líquido sem encostar os lábios no recipiente (um costume da terra incorporado pelos colonizadores). Os recém-chegados, não sabendo usar esses copos, acabam se molhando, o que é causa de desprezo pelos outros, pois "eles não sabem se comportar da maneira grave e cerimoniosa que os portugueses adotam na Índia". ${ }^{30}$ Essa gravidade e cerimônia parecem ser adotadas como forma de distinção pela minoria portuguesa e mestiça na cidade: todos se tratam com mesuras e ficam mortalmente ofendidos se não são cumprimentados quando se encontram pelas ruas, mesmo os mais pobres. 0 texto implica que o comportamento solene é diferente do que se encontra em Portugal. Ele é adotado na realidade do contato, informada pela percepção do ganho simbólico que traz na relação com os nativos e dentro da própria comunidade. 
As mulheres são tema de um capítulo inteiro. Nele, fica a sensação de que as indianas (convertidas ao catolicismo) e as mestiças envolvidas nos casamentos mistos são a grande porta de entrada para a degeneração dos portugueses. Elas são vigiadas ferozmente, mas sua perfídia sempre derrota os maridos. Mantêm os costumes da terra dentro de casa, com seus banhos aromáticos e o betéle que mascam compulsivamente. 0 casamento é a rota para a ruína dos portugueses, submetidos como estão ao adultério endêmico de suas mulheres indianas.

Estranhamente, ele começa sua descrição salientando a pudicícia dessas esposas. Elas raramente saem de casa, a não ser para ir à igreja ou visitar umas as outras. Quando saem, estão totalmente cobertas, e viajam dentro de palanquins, escondidas por tapetes e cortinas. Quando um homem bate à porta de suas casas, escondem-se imediatamente, e não permanecem em presença nem mesmo de seus filhos adultos, o que não dizer de outros homens. Mas esse cerco todo não detém o próprio Linschoten, que consegue dar detalhes até de como elas se vestem em casa. Usam uma camisa quase transparente que não chega ao umbigo, e um pano enrolado na cintura. Os soldados portugueses são, segundo Linschoten, geralmente sustentados por essas mulheres, que chegam a manter três amantes. Elas drogam seus maridos com datura, um alucinógeno, para manter seus encontros furtivos. De nada adiantam as medidas de precaução dos homens portugueses, inclusive 0 assassinato das mulheres flagradas em adultério: eles sempre são enganados. Novamente, os casamentos mistos engendram degeneração, aqui da própria virilidade dos homens portugueses. A simples conversão ao catolicismo não elimina os vícios das mulheres de uma raça que ele considera naturalmente inclinada à traição.

A narrativa prossegue sem trégua: decaídos racial e culturalmente, preguiçosos e traídos pelas mulheres, os portugueses são também corruptos. Seu sistema de mandatos de três anos nos cargos administrativos é zelosamente ridicularizado por Linschoten. A incessante busca de mercês e favores também não escapa a seu olhar. 0 quadro que fica da vida portuguesa em Goa é de decadência inescapável.

\section{Conclusão}

Linschoten é, obviamente, observador da vida indiana, independentemente da presença portuguesa. Seu texto é, por isso, ele próprio um documento etnográfico da primeira modernidade. Mas é também um cuidadoso narrador do modo de vida português nas terras da conquista. Assim, ele nos informa, em segunda ordem, sobre os pressupostos dos colonizadores no estabelecimento de sua relação com os nativos e no governo de si: sua etnografia implícita, que levou parte deles a aceitar a mistura racial por meio dos casamentos. Essa mistura é a raiz da desordem da vida portuguesa na Índia. Eles não aprenderam a lição mais básica da empreitada colonial: manter distância segura. Não foram capazes de criar um sistema de conhecimentos para governar a própria conduta, misturaram-se perigosamente ao elemento nativo, e agora sofrem as consequências disso.

0 texto é ainda notável como conhecimento produzido sobre o Império Português, em diversos aspectos. Trata detalhadamente da história natural da Índia, de práticas de cura, hábitos e religiões das populações que se encontram temporária ou permanentemente em Goa (em variados tipos de relacionamento com os portugueses, portanto). Trata-se de um documento importante que fez circular amplamente pela Europa diversas formas de saber a respeito do Estado da Índia, e tomou parte na conformação de empreitadas imperiais concorrentes da portuguesa (particularmente a holandesa, a inglesa, a francesa e a dinamarquesa). Essas empreitadas foram animadas por seus próprios sistemas de conhecimento e informadas por percepções do outro e de si mesmo - suas etnografias implícitas - que podem ter sido, de alguma maneira, tributárias das informações divulgadas por Linschoten a respeito da experiência portuguesa. 


\section{Notas e referências bibliográficas}

Thomás A. S. Haddad é doutor em Ciências. Professor de História das Ciências, Escola de Artes, Ciências e Humanidades da Universidade de São Paulo (EACH/ USP).Email: thaddad@usp.br.

1 Citado por SANTOS, Catarina Madeira. Administrative knowledge in a colonial context: Angola in the $18^{\text {th }}$ century. British Journal for the History of Science, v. 43, p. 539-556, 2010

2 A análise clássica dessa modalidade de saber se encontra em COHN, B. Colonialism and its forms of knowledge. Princeton: Princeton University Press, 1996.

3 XAVIER, Ângela Barreto. "O orientalismo católico. Rotinas do saber na Goa da época moderna". In: CONFERÊNCIA NO SIMPÓSIO INTERNACIONAL NOVOS MUNDOS - NEUE WELTEN. PORTUGAL E A ÉPOCA DOS DESCOBRIMENTOS. Trabalho... Berlim: Deutsches Historisches Museum, 2006. p. 4.

40 locus classicus para essa visão é o famoso artigo de BASALLA, George. The spread of Western science. Science, v. 156, p. 611-622, 5 mai. 1967.

5 A mais rica fonte a respeito desse movimento são os ensaios coligidos em PETITJEAN, Patrick; JAMI, Catherine; MOULIN, Anne-Marie (Ed.). Science and empires: historical studies about scientific development and European expansion. Dordrecht/Boston: Kluwer Academic Publishers, 1992.

6 Ver, por exemplo, PESET, José Luis. Ciencia e independencia en la América española. In: LAFUENTE, A.; ELENA, A.; ORTEGA, M. L. (Ed.). Mundialización de la ciencia y cultura nacional. Madri: Doce Calles, [s.d.]. p. 195-218.

7 De alguma forma, essa "hibridização" é analisada por GRUZINSKI, Serge. Les quatre parties du monde. Histoire d'une mondalisation. Paris: Les Éditions de La Martinière, 2004. Para a nova narrativa da "ciência global", ver RAJ, Kapil. Relocating modern science: circulation and the construction of knowledge in South Asia and Europe, 1650-1900. Hampshire: Palgrave Macmillan, 2007; e ROBERTS, Lissa. Situating science in global history: local exchanges and networks of circulation. Itinerario, v. XXXIII, p. 9-30, 2009. Impossível deixar de pensar nas reflexões de Joseph Needham como precedentes, ainda que radicalmente revisadas: NEEDHAM, Joseph. The grand titration: science and society in East and West. Londres: Allen \& Unwin, 1969.

8 Para uma discussão do papel do encontro de culturas na mecânica celeste de Newton, aparentemente (e só aparentemente) afastada dos saberes necessários à manutenção de um império, ver: SCHAFFER, Simon. Newton on the Ganges: the Asiatic enlightenment of British astronomy. In: HARRY CAMP MEMORIAL LECTURE. Trabalho... Stanford University, 2008.

90 tema da zona de contato é amplamente desenvolvido por PRATT, Mary Louise. Imperial eyes: travel writing and transculturation. 2. ed. Londres: Routledge, 2008.

10 SCHWARTZ, Stuart B. Introduction. In: (Ed.). Implicit understandings: observing, reporting and reflecting on the encounters between Europeans and other peoples in the early Modern Era. Cambridge: Cambridge University Press, 1995. p. 1-22.

11 SCHWARTZ, op. cit., p. 2-3. Esta e as demais citações de originais em língua estrangeira foram livremente traduzidas para este artigo.

12 SCHWARTZ, op. cit., p. 3

13 Ver, por exemplo, COOK, H. J. Matters of exchange: commerce, medicine, and science in the Dutch Golden Age. New Haven: Yale University Press, 2007.

14 As informações desta seção vêm do próprio LINSCHOTEN, J. H. van. The voyage of John Huyghen van Linschoten to the East Indies. Edição de A. C. Burnell e P. A. Tiele do texto inglês de 1598. 2 vol. Londres: Hakluyt Society, 1885. v. I, p. 1-23; v. II, p. 160-225; e de TIELE, P. A. Introduction. In: LINSCHOTEN, op. cit., p. XXIII-XLII; KOEMAN, C. Jan Huygen van Linschoten. Lisboa: IICT, 1984; BOOGAART, Ernst van. Civil and corrupt Asia. Chicago: University of Chicago Press, 2003; e SALDANHA, Arun. The itineraries of geography. Annals of the Association of American Geographers, v. 101, p. 149-177, 2011.

15 Itinerario, voyage ofte schipvaert van Jan Huygen van Linschoten naer Ooste ofte Portugaels Indien [Itinerário, viagem ou navegação de Linschoten às Índias Orientais ou Portuguesas]. Amsterdã: Cornelis Claesz, 1596. Neste trabalho, utilizamos a versão inglesa de 1598, na edição de 1885 da Hakluyt Society (Londres), anotada por BURNELL, op. cit, e TIELE, op. cit.

16 LINSCHOTEN, op. cit., v. I, p. 1-2

17 Apud TIELE, op. cit., p. XXIV

18 Uma gravura de 1595, publicada no Itinerario, informa sua idade em 32 anos.

19 António da Silva Rego traz apenas duas entradas sobre o arcebispo, nenhuma das quais de interesse aqui. REGO, António da Silva. Documentação para a história das missões do Padroado Português do Oriente: Índia. Lisboa: Fundação Oriente e Comissão Nacional para as Comemorações dos Descobrimentos Portugueses, 1991-2000.

20 BOOGAART, op. cit., p. 1.

21 A história dos portugueses na Índia é muito bem descrita por SUBRAHMANYAM, Sanjay. 0 império asiático português 1500-1700: uma história política e económica. Linda-a-Velha: Difel, 1995; e por PEARSON, Michael N. The Portuguese in India. Cambridge: Cambridge University Press, 1987.

22 É o que se depreende de THOMAZ, Luís Filipe F. R. De Ceuta a Timor. Linda-a-Velha: Difel, 1994. p. 456-480; ou de BOUCHON, Geneviève. Premières expériences d'une société coloniale: Goa au XVI ${ }^{\mathrm{e}}$ siècle. In: Fundação Calouste Gulbenkian, 1999. p. 204-225.

23 Para o maravilhoso circulando entre a Índia e a Península Ibérica nos séculos XVI e XVII, ver FLORES, Jorge. Distant wonders. Comparative Studies in Society and History, v. 49, p. 553-581, 2007.

24 BARRETO, Luis Filipe. Descobrimentos e renascimento: formas de ser e pensar nos séculos XV e XVI. Lisboa: Imprensa Nacional, 1982; e SILVA DIAS, J. S. da. Os descobrimentos e a problemática cultural do século XVI. Coimbra: Universidade de Coimbra, 1973

25 KAMPS, Ivo. Colonizing the colonizer: a Dutchman in Ásia Portuguesa. In: KAMPS, I.; SINGH, J. G. Travel knowledge: European "discoveries" in the early Modern Period. Hampshire: Palgrave Macmillan, 2001. p. 160-184. 
26 LINSCHOTEN, op. cit., v. I, p. 183-184.

27 PEARSON, op. cit., p. 105.

28 BOXER, Charles R. Race relations in the Portuguese colonial empire, 1415-1825. Oxford: Clarendon Press, 1963.

29 LINSCHOTEN, op. cit., v. I, p. 185

30 LINSCHOTEN, op. cit., v. I, p. 208.

[Recebido em agosto de 2011, aprovado para publicação em novembro de 2011] 